\title{
Effects of adding sisal and glass fibers on the mechanical behaviour of concrete polymer
}

\author{
Benzannache $\mathrm{N}^{1}$, , Bezazi $\mathrm{A}^{2}$, Bouchelaghem $\mathrm{H}^{2,3}$, Boumaaza $\mathrm{M}^{1}$, Scarpa $\mathrm{F}^{4}$, Amziane $\mathrm{S}^{5}$ \\ 1 Laboratory of Civil Engineering \& Hydraulics (LGCH)/Guelma University, Algeria \\ 2 Laboratory of Applied Mechanics of New Materials ((LMANM)/University of Guelma, Algeria \\ 3 Department of Mechanical Engineering/University of Constantine1, Algeria \\ 4 Advanced Composites Center for Innovation and Science (CCCTB)/University of Bristol, UK \\ 5 Department of Civil Engineering, Polytech Clermont Ferrand/Blaise Pascal University, France \\ * Corresponding author: zanachenaziha@yahoo.fr, benzannache.naziha@univ-guelma.dz
}

Received: 07-02-2018 Revised: 19-04-2018 Accepted: 07-05-2018

\begin{abstract}
In this study, we investigated the influence of the addition of sisal and glass fibres on the mechanical properties of polymer concrete (PC). These types of concrete are used in many modern civil engineering applications. The prismatic specimens sized according to ASTM C580-02 were elaborated with a PC constituted by 14\% constant mass of polyester resin matrix, a granular skeleton based on sand and powder marble. The reinforcement with $60 \%$ sand and $26 \%$ marble powder adopted in this investigation is the best formulation found in previous authors work. This composition was reinforced by 1 and $2 \%$ of sisal and glass fibres, the first one having lengths of $6 \mathrm{~mm}$ or $12 \mathrm{~mm}$, however, the second unidirectional cut into bands. These specimens were subjected to 3-point bending monotonic loading. The results obtained were discussed and compared with those obtained for control beams without fibres reinforcement. It is important to note that the incorporation of the glass fibre contributes to an increase of the ultimate load of the polymer composite material produced, however, the addition of the sisal fibre lead to its decreases. In addition, the incorporation of $2 \%$ of sisal fibre having $6 \mathrm{~mm}$ length leads to a reduction of $26 \%$ of the mass of the specimens.
\end{abstract}

Key words: Polymer concrete, sisal and glass fibres, marble, resin, sand.

\section{Introduction}

Polymer concrete (PC) is a material manufactured completely or partially by replacing the Portland cement with a polymer. Since the 1980s, research and development of polymer concrete and mortars have been growing rapidly in various Western countries. The substitution of Portland cement with a polymer results in a substantial increase in the cost of concrete, this should only be done if the cost of labour is lower or if the energy requirements for manufacturing and implementation are lower (Blaga and Beaudoin, 1985).

At present, the PC can be used very efficiently due to its high strength and lightness, made of prefabricated elements in the building, such as: bridge decks, hazardous waste containers, industrial machine bases, floor tile manufacture with synthetic marble and stair panels, facade panels and panels of various structures and window sills (Ohama, 2010).

To improve the physical and mechanical properties, researchers have been interested in optimizing the PC formulation by reducing the resin mass fraction and/or replacing or adding part of the granular skeleton by other components (Gorninski, 2004; Haidar, 2011; Elalaoui, 2012). As a result, the PC's qualities are improved while respecting economic requirements.

Moreover, the growing demand for environmentally friendly materials has led researchers to focus on the incorporation into the PC, industrial waste residue as reinforcement (fly ash, tire rubber, foundry sands, glass powder waste, marble powder etc...) to make one hand more powerful, lighter and less costly (Bignozzi, 2000 ; Ribeiro, 2013). Castro et al.(2013), Saribiyik et 
al. (2013) found that the incorporation of a $30 \%$ amount of glass powder waste into the PC leads to an increase in bending and compression stresses by 78 and $29 \%$ respectively.

In order to reduce the cost of PC produced with synthetic fibres (ie carbon, Kevlar, glass, etc.), the latter are replaced by natural fibres such as jute, sisal, flax, coco, banana, etc., which have gained considerable importance as reinforcements in polymer matrix composites. Compared to synthetic fibre, natural ones issue from plants (lignocelluloses) has the advantage of being very light, issue from a renewable source, cheap and widely available in fibrous form.

In a study conducted by Reis (2006) using $2 \%$ of the coconut, bagasse (sugar residue) and banana fibres as addition in the PC. He concluded that coconut and bagasse fibres improve the mechanical properties of PC both its strength and its breaking energy, while banana fiber has only increased the breaking energy. In other words, coconut fibre proves to be an excellent reinforcement for PC thus increasing its ultimate bending strength by $25.1 \%$. While, banana stem fibres is not a good choice for strengthening PC (Reis, 2006).

In another work, Reis (2012) studied the effect of the incorporation of the treated and untreated sisal fibres with $\mathrm{NaOH}$ and acetic acid into two polymeric mortars, based on epoxy and polyester resins respectively. The addition of a small quantity of sisal fibres contributes significantly to the improvement of the mechanical properties of the PCs. It has also been observed that polymer mortars reinforced with untreated sisal fibres have the highest ultimate strength and those reinforced with sisal fibres treatment with $10 \%$ of $\mathrm{NaOH}$ have the lowest properties.

Benzannache et al. (2018) have shown in an earlier study that the incorporation of marble waste has improved the mechanical and physical properties of polymer concrete. For this purpose, the main objective is to study the effect of the additions on the mechanical strength of the PC beams subjected to 3-point bending. The PC constituted of resin, marble powder waste, sand granulate as well as $1 \%$ or $2 \%$ additions of the glass fibre in the form of bands located at tensile zone precisely at $1 / 3$ of the height of the beam. In addition, beams with the incorporation of sisal fibre cut in two different lengths $(6 \mathrm{~mm}$ and $12 \mathrm{~mm})$ and randomly distributed in the mass have been also studied.

\section{Experimental protocol}

\subsection{Study Materials}

Previous work by the authors Benzannache et al. (2018) revealed that the best flexural behaviour of the PC (designed as GC60 M26) was obtained with 14\% of a polyester resin matrix, $60 \%$ of a granular skeleton (sand of particle size $1-3 \mathrm{~mm}$, steamed at $105^{\circ}$ ) and $26 \%$ marble powder waste of particle size (0.02-1.4 mm).

The present work consists of substituting 1 or $2 \%$ of the sand aggregate with glass fibre in the form of bands or sisal fibre cut into 6 or $12 \mathrm{~mm}$ lengths and randomly distributed in the mass. The characteristics of this type of glass fibre are determined in previous work, by Bouchelaghem et al. (2011), done in the laboratory of applied mechanics (LMANM of the University of 8 Mai 1945 Guelma Algeria). While, the sisal fibre are also characterised in laboratory LMANM by Belaadi et al. (2013), (2014). The seven prepared formulations are shown in Table 1.

\subsection{Preparation}

The seven formulations of PC can be classified into three groups: the first is a polymeric concrete control (PC_control), the second consists of four PCS formulations with $1 \%$ or $2 \%$ sisal fibre having a length of 6 or $12 \mathrm{~mm}$. As for the last group contains two formulations PCG which is added 1 to $2 \%$ of glass fibre bands. 


\section{- Concrete PC_control}

The constituents of the PC_control are weighted and dry-mixed and then a polyester resin, previously prepared with $1.5 \%$ hardener and $1 \%$ accelerator, is added to the mixture. The mixture thus obtained will be placed in prismatic moulds of dimensions $25 \times 25 \times 300 \mathrm{~mm}$ according to ASTM C580.02.

Table 1. Formulations of the PC.

\begin{tabular}{|l|c|c|c|c|c|c|c|c|}
\hline Formulation & $\begin{array}{c}\text { Resin } \\
(\%)\end{array}$ & $\begin{array}{c}\text { Sand } \\
(\%)\end{array}$ & $\begin{array}{c}\text { Marble } \\
(\%)\end{array}$ & $\begin{array}{c}\text { Sisal } \\
(\%)\end{array}$ & $\begin{array}{c}\text { Glass fibre } \\
(\%)\end{array}$ & $\begin{array}{c}\text { Average } \\
\text { specimen } \\
\text { Weight M(g) }\end{array}$ & $\begin{array}{c}\text { Decrease } \\
\text { in weight } \\
\text { Df }(\%)\end{array}$ & $\begin{array}{c}\text { Density } \\
\left(\mathrm{Kg} / \mathrm{m}^{3}\right)\end{array}$ \\
\hline \hline PC_control & 14 & 60 & 26 & 0 & 0 & 419.60 & 0 & 2237.87 \\
\hline PCS_1\%_6mm & 14 & 59 & 26 & 1 & 0 & 355.60 & 15.25 & 1896.53 \\
\hline PCS_1\%_12mm & 14 & 59 & 26 & 1 & 0 & 336.97 & 19.7 & 1797.17 \\
\hline PCS_2\%_6mm & 14 & 58 & 26 & 2 & 0 & 320.94 & 23.5 & 1711.68 \\
\hline PCS_2\%_12mm & 14 & 58 & 26 & 2 & 0 & 310.50 & 26.0 & 1656.0 \\
\hline PCG_1\% & 14 & 59 & 26 & 0 & 1 & 413.26 & 1.5 & 2204.05 \\
\hline PCG_2\% & 14 & 58 & 26 & 0 & 2 & 388.37 & 7.3 & 2076.31 \\
\hline
\end{tabular}

- Concrete PCS:

For this type of concrete the sisal, having a length of 6 or $12 \mathrm{~mm}$, has been incorporated and mixed well with the dry granulates. The prepared resin is then added gradually while mixing until the PCS is obtained, which is then poured into the mould may contain seven specimens (Figure 1).

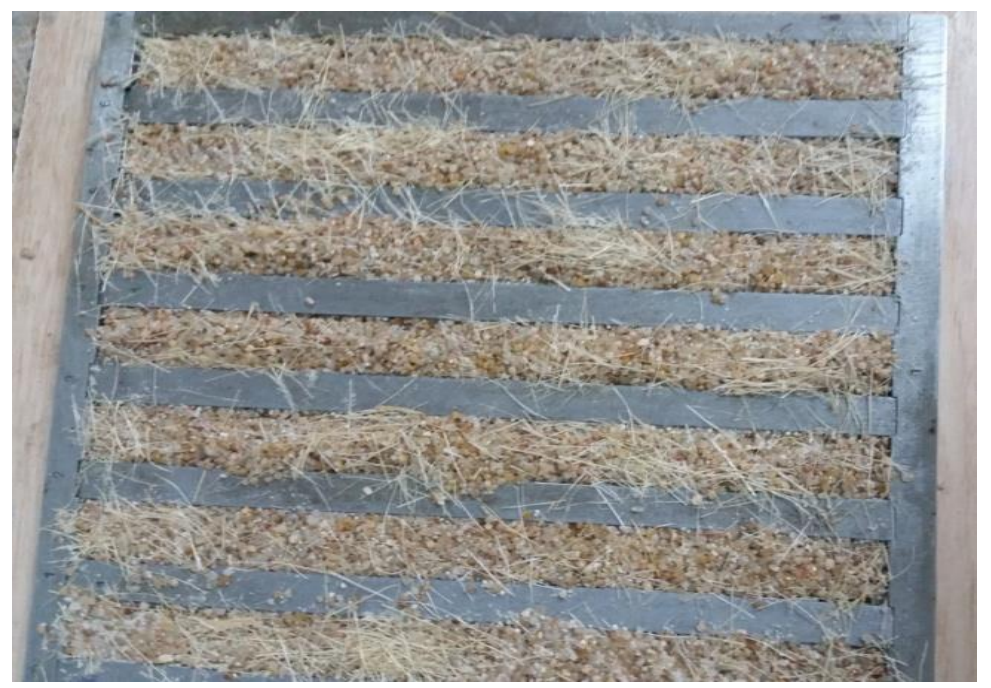

Fig 1. Mould filled with PCS may contain seven specimens.

\section{- Concrete PCG:}

The same procedure for preparing the control concrete, only this time, 1 or $2 \%$ of sand is substituted by the glass fibre bands of size $25 \times 300 \mathrm{~mm}$ impregnated with resin and spread out 
at $1 / 3$ of the height of each beam specimens, then continue until the mould is completely filled (Figure 2).

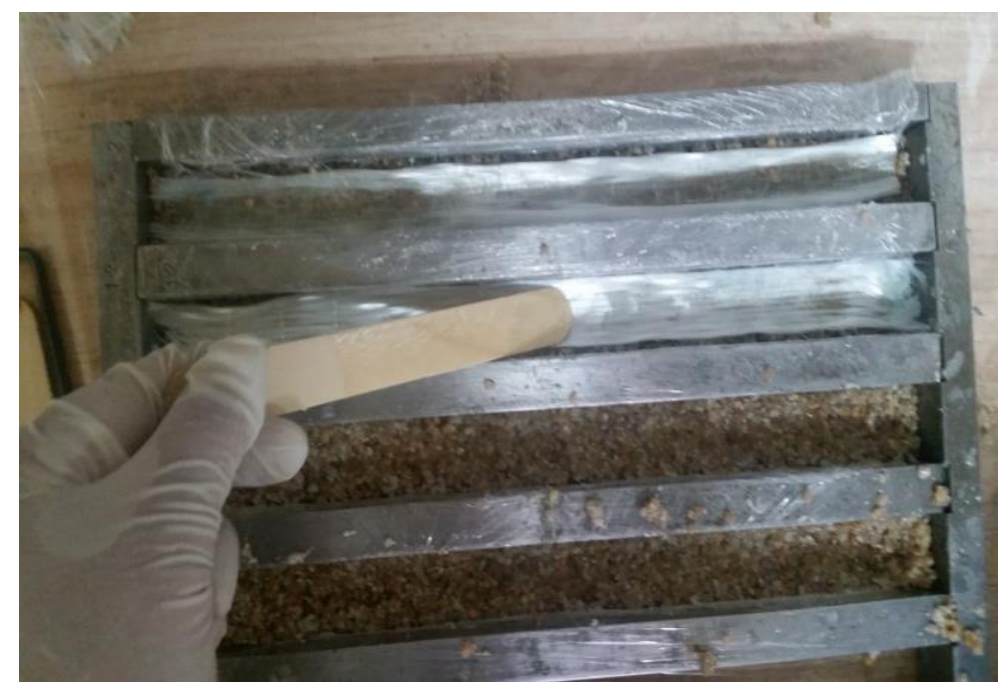

Fig 2. Filling of mould with the glass fibre band incorporations.

\subsection{Experimental setup}

The static 3-point bending tests were carried out on a Zwick/Roell Z005 universal testing machine at a test speed of $2 \mathrm{~mm} / \mathrm{min}$. This machine is equipped with a load cell whose capacity is $20 \mathrm{kN}$ (Figure 3).

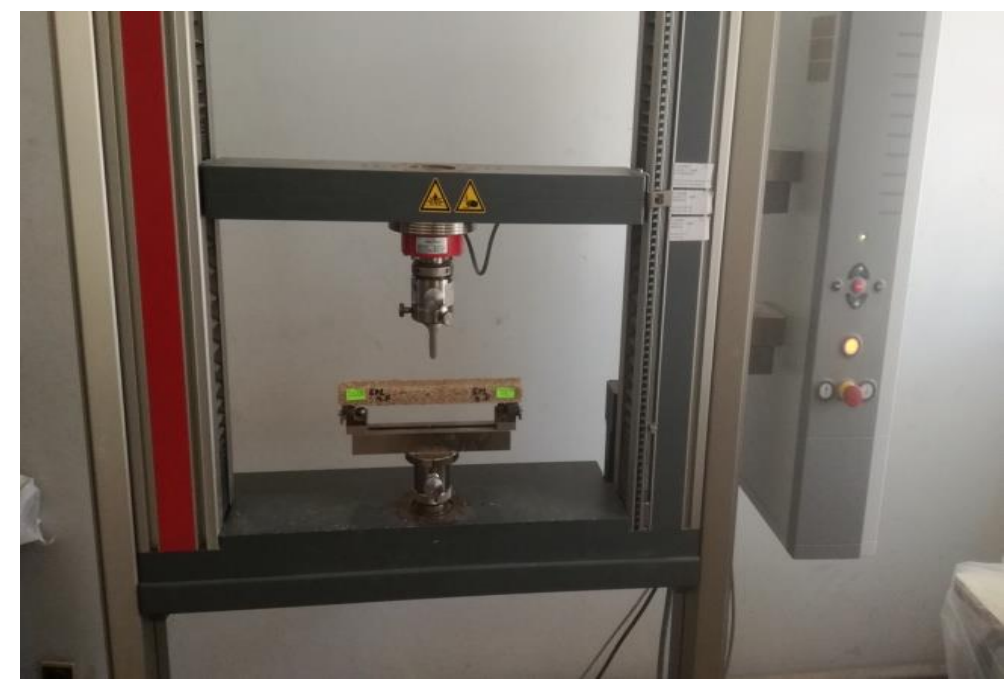

Fig 3. Experimental setup.

\section{Results and discussion}

\subsection{Bending behaviour of PCs}

The loads/displacements behaviour of the control beams presented in Fig.4 occur in two phases: the first one is practically linear until reaching the ultimate load, while sometimes small staircase shapes are noted due to the detachment of sand grains (see Figure 4, PC5_control). The second short phase is characterized by a sudden drop of force leading to the specimen failures.

It is also important to note that at the beginning of the tests, a displacement with a small force is recorded before the actual response of the material starts. The average ultimate load is of the order of $800 \mathrm{~N}$ for an average displacement at failure of $0.80 \mathrm{~mm}$. With the incorporation of the 
sisal fibre (Figures 5a to 5d), the evolution of the load/displacement curves is similar to that obtained for the control concrete, nevertheless with more pronounced perturbations in the first phase with a less brutal drop in the load at the second phase.

The addition of the sisal fibre provoke an absorption of resin, leading to an insufficient sticking between the grains, this causes more grain detachment which results in staircase perturbations in the response curves.

The load is reduced for all the test specimens, for the incorporation of 1 or $2 \%$ of sisal fibre having lengths of 6 or $12 \mathrm{~mm}$. The maximum recorded loads for the beams PCS_1\%_6, PCS_1\%_12, PCS_2\%_6 and PCS_2\%_12 are respectively 612, 583, 405 and $396 \mathrm{~N}$ and their corresponding to a reduction of $30 \%, 37 \%, 97 \%$ et $102 \%$ comparatively to the control concrete. While, their displacements at failure are 1.24, 1.25, 1.22 and $3.03 \mathrm{~mm}$ respectively corresponding to an increase by $55 \%, 56 \%, 52 \%$ et $378 \%$ respectively. In other words, it was found that cut sisal fibre did not lead to improve the ultimate load on the contrary, it decreased it, however the displacement increased for the best case by $269 \%$ for the specimens containing $2 \%$ of sisal fibres having $12 \mathrm{~mm}$ length. It is important to note that the incorporation of the sisal fibres can lead to a decrease up to $26 \%$ of the specimen mass compared to the control one; this is obtained in the case of the addition of $2 \%$ of sisal having $12 \mathrm{~mm}$ length (see Table 1 ).

The load/displacement behaviour of the beams reinforced by unidirectional glass fibre bands is shown in (Figures 5e and 5f). This behaviour, which occurs in three phases, is different from that of the control beams and those reinforced by sisal fibres because it has allowed to a considerable increases both in load and displacement. The first linear phase up to a force of about $800 \mathrm{~N}$ corresponding to that found for the concrete control.

The second phase is also linear but with lower slope than the first phase and shows disturbances. The average ultimate loads and displacements at failure reached are 2040, $2740 \mathrm{~N}$ and 11.3, $10.5 \mathrm{~mm}$ respectively for the beams PCG_1\% and PCG_2\%. Finally, a staircase is observed leading to a less brutal failure compared to those found for the control beams and the ones reinforced with sisal fibre.

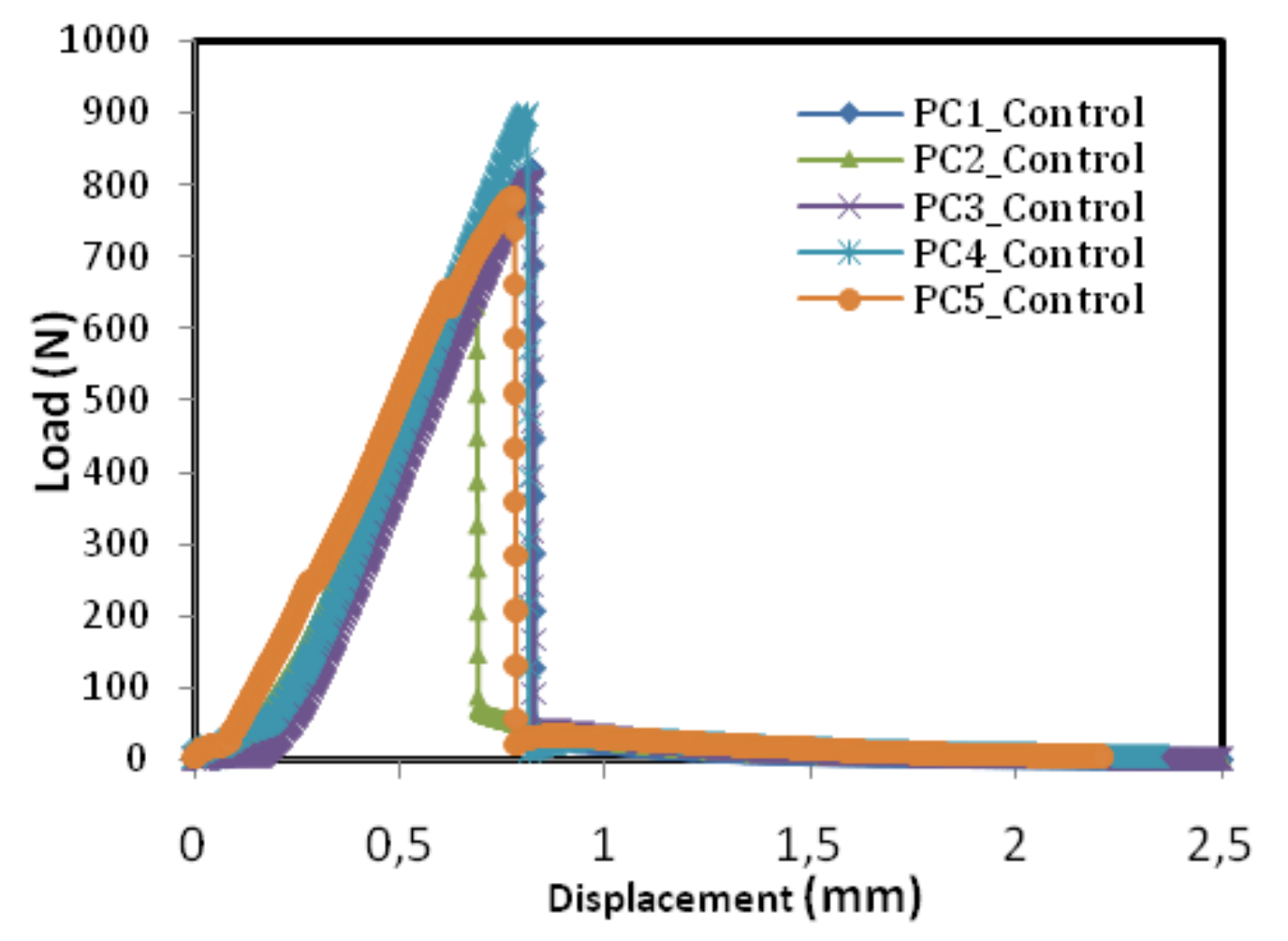


Fig 4. Load/displacement of PC-control.
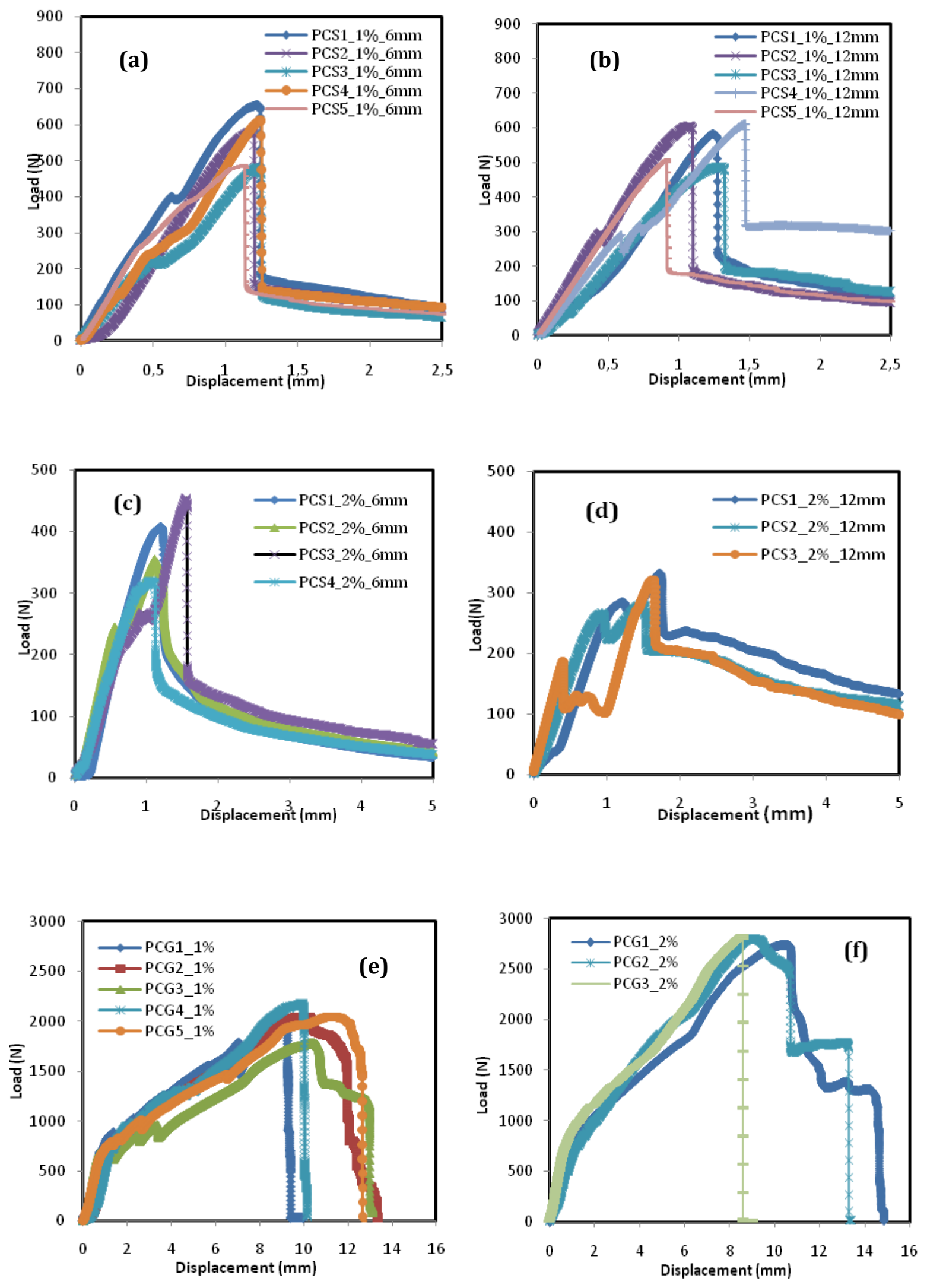

Fig 5. Load/displacement of different PCs: a) PCS_1\%_6 mm; b) PCS_1\%_12mm; c) PCS_2\%_6mm; d) PCS_2\%_12mm ; e) PCG_ 1\% ; f) PCG $2 \%$. 
The comparisons of the behaviour of the control PC with PCs reinforced by the sisal or glass fibres are shown in (Figure 6). The analysis of the results shows clearly that the addition of the glass fibre bands leads to the best behaviour. Indeed, the addition of 1 or $2 \%$ glass fibres allows to an average increase in ultimate load by 153 and 238\% respectively and their corresponding displacements by 1281 and $1180 \%$.

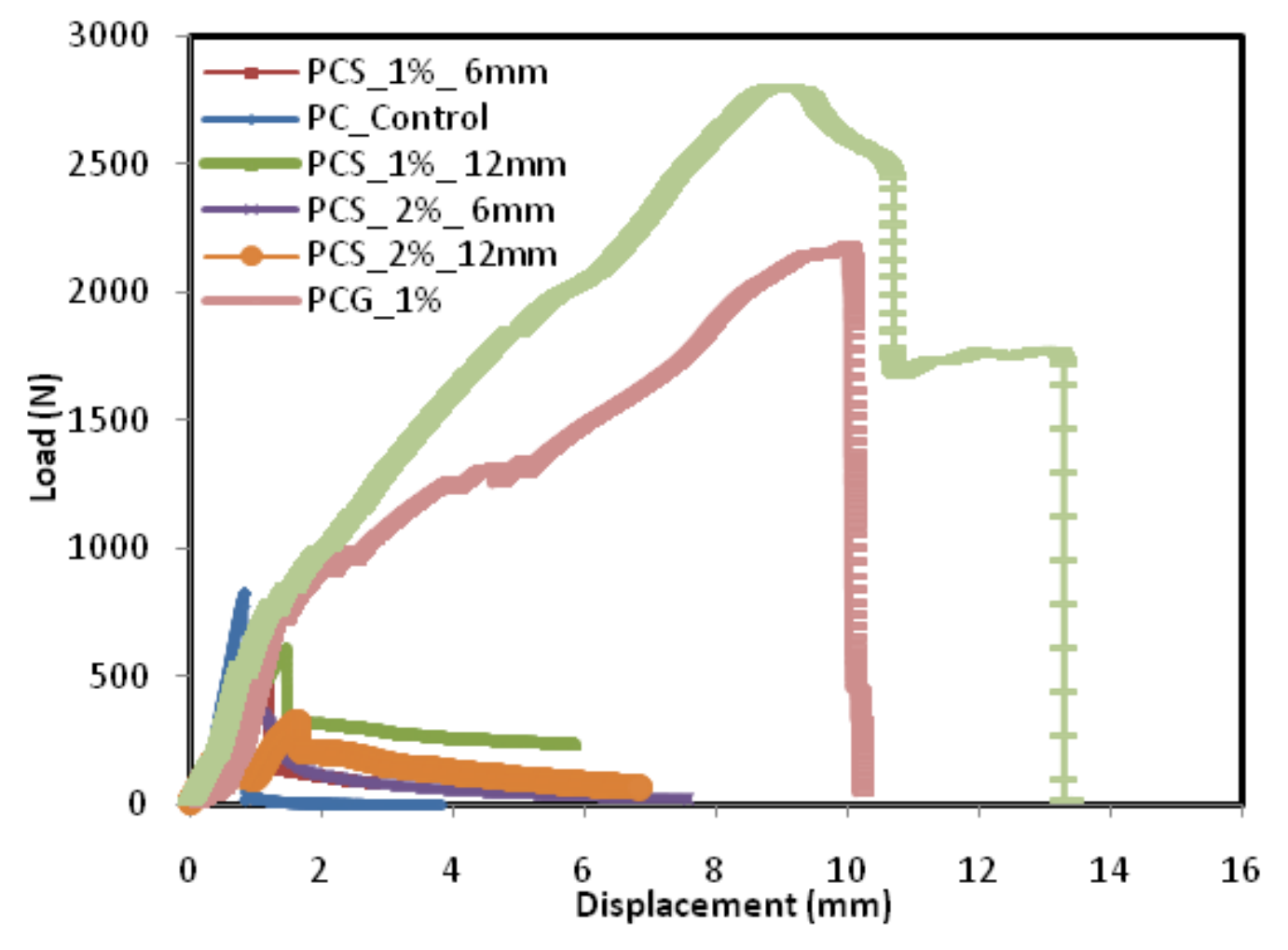

Fig 6. Load/displacement curves of the PCS and PCG compared to the control concrete (PC_control).

\subsection{PCs failure modes}

Figure 7 shows the different failure modes of the PCs specimens where the cracks are initiated at the tensile zone (bottom surface). For the concrete control beams PC, the failure was brutal leading to divide the specimen in two parts (Figures $7 \mathrm{a}$ and $7 \mathrm{~b}$ ). While, for beams reinforced with sisal fibre (PCS), the failure is less brutal and the crack initiated cannot reach the face application load (Figures 7c to 7f).

Whereas, for the beams reinforced with $1 \%$ or $2 \%$ of glass fibre bands, the failure occurs on three steps following the load/displacement behaviour. The crack initiated in the tensile zone propagates until reaching the composite (step 1), this corresponds to the first phase of the curve load/displacement (Figure 7g). The composite slows the failure propagation until it broke (step 2) where a new crack appear and develop until the top surface (step 3) leading to compression failure of the concrete. The step 2 and 3 are representing the phase two and three of the PCGs Load/displacement behaviour (Figure 7h). 

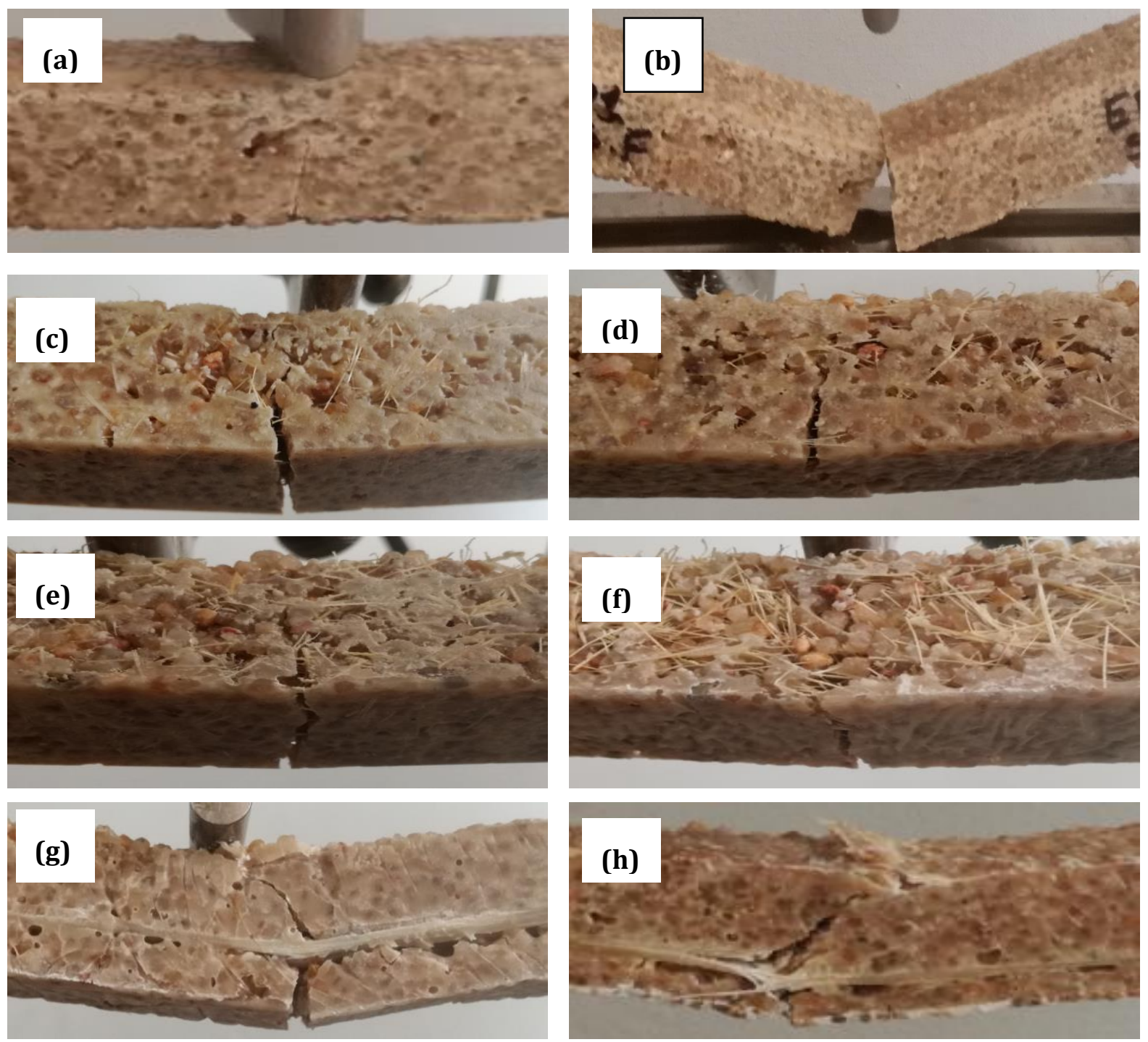

Fig 7. Rupture facies : a) Crack initiation of control beam, b) Failure control beam ; c) EPS-1\%_6 ; d) EPS$1 \% \_12$;e) EPS-2\%_6 ; f) EPS-2\%_12 ; g) EPV-1\% ; h) EPV-2\%.

\section{Conclusions}

The study of the flexural mechanical behaviour of polymer concrete with the incorporation of 1 or $2 \%$ of sisal or glass fibre leads to the following points:

- The addition of the sisal fibre cut and mixed randomly, allows a reduction in the mass of the specimens up to $26 \%$ compared to the control specimen. On the other hand, decreases in ultimate load with a slight increase in displacements are recorded.

- The sisal fibre causes the absorption of the resin and therefore the $14 \%$ is not sufficient to agglomerate the grains, this causes the separation of the grains which leads to the appearance of the forms in staircase (abrupt decrease of load).

- Incorporation of the unidirectional glass fibre strips introduced at $1 / 3$ of the height of the specimens allowed the improvement of the mechanical characteristics. Indeed, the addition of 1 or $2 \%$ of glass fibre has increased the ultimate loads and displacements by $153,238 \%$ and $1280,1180 \%$ respectively. 
Acknowledgments: The authors are great full to Prof. REDJEL B. and Prof. MERZOUD M. from the laboratory LGC University of Annaba having to facilitate access to their machine for the experiment tests.

\section{References}

Belaadi, A., Bezazi, A., Bourchak, M., \& Scarpa, F. (2013). Tensile static and fatigue behaviour of sisal fibres. Materials \& Design, 46, 76-83.

Belaadi, A., Bezazi, A., Bourchak, M., Scarpa, F., \& Zhu, C. (2014). Thermochemical and statistical mechanical properties of natural sisal fibres. Composites Part B: Engineering, 67, 481-489.

Benzannache, N., Bezazi, A., Bouchelaghem, H., Boumaaza, M., Amziane, S., \& Scarpa, F. (2018). Statistical analysis of the 3-point bending properties of polymer concrete made of marble powder waste, sand grains and polyester resin. Mechanics of Composite Materials, 53(6), 1123-1136.

Bignozzi, M. C., Saccani, A., \& Sandrolini, F. (2000). New polymer mortars containing polymeric wastes. Part 1. Microstructure and mechanical properties. Composites Part A: applied science and manufacturing, 31(2), 97-106.

Blaga, A., \& Beaudoin, J. J. (1985). Polymer modified concrete. Canadian building digest, CBD-241. Institute for Research in Construction.

Bouchelaghem, H., Bezazi, A., \& Scarpa, F. (2011). Compressive behaviour of concrete cylindrical FRPconfined columns subjected to a new sequential loading technique. Composites Part B: Engineering, 42(7), 1987-1993.

Castro, A. M., Ribeiro, M. C. S., Santos, J., Meixedo, J. P., Silva, F. J., Fiúza, A., ... \& Alvim, M. R. (2013). Sustainable waste recycling solution for the glass fibre reinforced polymer composite materials industry. Construction and Building Materials, 45, 87-94.

Elalaoui, O., Ghorbal, E., Mignot, V. \& Ben Ouezdou, M. (2012). Mechanical and physical properties of epoxy polymer concrete after exposure to temperatures up to $250{ }^{\circ} \mathrm{C}$. Construction and Building Materials, 27, 415-424.

Gorninski, J. P., Dal Molin, D. C., \& Kazmierczak, C. S. (2004). Study of the modulus of elasticity of polymer concrete compounds and comparative assessment of polymer concrete and portland cement concrete. Cement and Concrete Research, 34(11), 2091-2095.

Haidar, M., Ghorbel, E., \& Toutanji, H. (2011). Optimization of the formulation of micro-polymer concretes. Construction and Building Materials, 25(4), 1632-1644.

Ohama, Y. (2010). Concrete-polymer composites: the past, present and future. $13^{\text {Th }}$ International Congress on Polymers in Concrete (ICPIC), Portugal, pp. 1-14.

Reis, J. M. L. (2006). Fracture and flexural characterization of natural fiber-reinforced polymer concrete. Construction and building materials, 20(9), 673-678.

Reis, J. M. L. (2012). Sisal fiber polymer mortar composites: Introductory fracture mechanics approach. Construction and Building Materials, 37, 177-180.

Ribeiro, M. C. S., Fiúza, A., Castro, A. C. M., Silva, F. G., Dinis, M. L., Meixedo, J. P., \& Alvim, M. R. (2013). Mix design process of polyester polymer mortars modified with recycled GFRP waste materials. Composite Structures, 105, 300-310.

Saribiyik, M., Piskin, A., \& Saribiyik, A. (2013). The effects of waste glass powder usage on polymer concrete properties. Construction and Building Materials, 47, 840-844. 